\title{
Small Steps Toward an Ethos of Partnership in a Hong Kong University: Lessons from a Focus Group on "Homework"
}

Elizabeth Ho, Department of English, Hong Kong University, Hong Kong Contact: lizho@hku.hk

\section{HISTORY: ESTABLISHING A PARTNERSHIP PROGRAM AT LINGNAN UNIVERSITY}

As a teacher at Lingnan University new to Hong Kong's classroom culture, I sought insight into the learning environment and feedback on the effectiveness of my delivery of material to non-native English speakers beyond end-of-term evaluations. To serve these needs, also shared by other instructors in this context, and in support of Lingnan's mission as a global, liberal arts institution, I created the Student Consultant Program as a collaboration with the Teaching and Learning Initiative at Ursinus College. Until it was able to develop its own identity and role, implementation of the Lingnan program relied heavily on Ursinus' Student Consultant Program. Since 2014, however, Lingnan's program has grown into a small but sustainable and successful program (Pounder, Ho, \& Groves, 2015). In the context of semester-long studentfaculty pedagogical partnerships, trained Student Consultants provide faculty across disciplines with feedback from the perspective of students not enrolled in their courses through regular classroom observations, dialogue, and critical reflection. ${ }^{1}$

As the faculty coordinator of the program, I organize partnerships, maintain records and evaluations, and mentor the small cohort of seven Student Consultants. As part of my research, I also catalog the unique characteristics and challenges that emerge from the Student Consultant Program's equally unique context as a teaching and learning resource in a liberal arts university, which is performing its mission in a heavily politicized, postcolonial environment. Students invited to join the program are usually the most curious about how they are taught, have high GPAs, and demonstrate excellent communication skills in English and in Cantonese. I hoped that the dialogue resulting from partnerships could not only support teachers in this context but also help students articulate their experience of Hong Kong's recent educational reforms. ${ }^{2}$

\section{Stepping Out: Seeking to Expand Partnership at Lingnan University}

In this historical context, and with the goal of further developing the Student Consultant Program, the Lingnan team (two Student Consultants and I) participated in the "Change Institute" at the McMaster University Summer Institute on Students as Partners held in 2017. As part of our discussion of sustainability, we explored how we could extend the dialogue 
beyond the Student Consultant/faculty partner dyad to include more student voices and perspectives on teaching and learning as well as develop an ethos of partnership that could encompass the entire campus. Key concerns for us were: how to attract students and faculty outside of the Student Consultant Program to experience and be empowered by the benefits of partnership (identified as the respectful sharing of ideas in an environment of more even power dynamics), and how to identify and exploit openings at the university for such encounters to flourish.

We agreed that one modest and achievable step was to host a focus group led by experienced Student Consultants that was attended by their current and ex-faculty partners and open to other students. For our inaugural focus group, we decided to offer participants one credit towards fulfilling the university's required Integrated Learning Program curriculum. The topic we chose was "homework," an activity that teachers and students have in common but with vastly different perspectives, goals, motivations, and outcomes. Especially in Cantonese, the term "homework" denotes almost all graded or ungraded assignments completed outside of class time. We hoped that the focus group would provide a forum for discovering different experiences of and perspectives on homework as well as the pedagogical intentions behind it so that both parties would be able to reflect on (and perhaps modify) their approaches to doing and assigning homework. As faculty partners were, in this instance, Westerners with a variety of Hong Kong experiences and students were local to Hong Kong, what emerged was a powerful discussion about cultural differences, differences between the adult and young adult culture, and systemic issues far beyond the assigning of homework.

\section{Designing and Facilitating a Focus Group on "Homework"}

In preparation for the focus group, the experienced Student Consultants and I met to discuss our own experiences of homework in Hong Kong and abroad and grappled with how to create partnership in one hour, under the fairly artificial constraints of participation for credit in a session that drew "good students with good attitudes, and teachers with good attitudes" (Professor A). We designed an informal icebreaker activity that would allow us to tackle different perspectives on homework: all participants wrote down one word that described their experience with homework and were asked to say why they had chosen it. Then, Student Consultants facilitated a larger discussion about different aspects of homework with questions such as, "To a student, what is the difference between reading and assignments?"; "What is the difference between homework in high school and university?"; and "What is your 'ideal' homework?" They chose these questions based on our discussion of why the university recommends six hours of outside study for every course and how faculty and students are expected to fill them.

For our first one-hour meeting, three Student Consultants from various departments invited their current faculty partners from business and the humanities and an ex-faculty partner from science; seven students across majors from different years also attended providing a total of ten students and four teachers. Student Consultants were responsible for leading with the questions that had been developed prior to the focus group-a shift in traditional dynamics that led to a more candid and rich discussion. In addition to revealing many insights about homework, our conversation highlighted how different assumptions can 
throw obstacles in the way of partnership and also how a key shift in attitude can open the way to partnership.

\section{Assumptions as Obstacles to Partnership}

A disagreement regarding plagiarism in the first focus group meeting threw into relief how different assumptions-in this case about the "effectiveness" of homework, what counts as "resources," and how "interesting" homework should be-can constitute significant obstacles to partnership. During the icebreaker activity, Student C explained that she chose the word "ineffective" to describe homework because there are simply too many "resources," such as Google or copying from her friends, and therefore her homework does not actually measure her understanding of the course materials. In response, another student reported that it was common to copy a classmate's homework from a previous class; another recalled an American exchange student who realized that his local presentation partner simply copied and pasted "quotes from the website, and put it in the PowerPoint ... hoping that the lecturer won't notice, and he ... can just kinda read from the PowerPoint and just get his mark" (Student F).

The reactions from faculty partners ranged from shock to despair with Professor $A, a$ new professor to Lingnan and Hong Kong, visibly stumped by such bold admissions of academic dishonesty. The mere mention of the "p-word" (i.e., plagiarism) threatened to become the focus of the discussion by shutting down faculty members' ability to hear or reflect on what students were trying to communicate. The divergence in the definition of and intentions behind copying, which the professor saw as dishonesty but which the student saw as a "resource," overwhelmed the original focus: the initial commenting student's choice of the adjective "ineffective."

Student participants persisted in explaining why they might choose to copy than turn in original work. Student C explained that she turns to "resources" such as "groupmates and friends" to help her complete homework tasks, noting that her homework was "very similar" to what her friends completed in a previous iteration of the class. Perhaps Student C's teacher was as pragmatic as the students $s /$ he teaches, saving time and effort by opting to re-assign homework instead of tinkering with an assignment that might ask a student to "think on my own." Reflecting on Student C's accountability as a student to produce original work, I am challenged to think about my own accountability as a teacher in creating an assignment that cannot be copied. What is my role in not creating what Student F called "rubbish" homework that is "made to grade you ... [and doesn't] teach you anything, it's the grade that you have to fulfill?"

Disagreements and strong emotional reactions emerged as the result of different assumptions made about what "ineffective" might mean, what counts as "resources," and what drives plagiarism. While students spent a significant portion of the focus group meeting trying to make clear to faculty that they prefer to think for themselves, to take risks, and to "expand our ideas," different student and faculty assumptions initially presented an obstacle to partnership.

A second issue, that of incentives, was equally challenging. During our discussion, students revealed that they do not consider reading as homework because, in the hierarchy of assignments to be completed outside of class time, reading is "worth" less. In part, reading 
comes last in the list of homework activities because it contributes the least to a student's measured success in the class. Hearing the students' perspectives, the teachers asked how they could pitch their activities and then assess the majority of the class who may not have done the reading. A few students divulged that the best incentive for reading-indeed, even for simply attending class regularly - is to make it worthwhile or "interesting."

Like "ineffective," "interesting" threatened to shut down what could be heard during the discussion because of the different assumptions students and faculty made about the term. All professors believe they assign "interesting" reading, and if it is not "interesting," then it is "good for you" or somehow necessary to the course. Students shared their responses to these beliefs, including, as Student F put it, not doing a single reading "except for White Elephant [George Orwell's "Shooting An Elephant"], because that one is interesting." She also explained why she did not go to class: "because it is compulsory, you don't need to be interested ... but you have to go there and just listen to the lecture." She argued that "the whole system is wrong, you are forcing students to go to the class they don't like, that's why they don't do their homework."

Her comments elicited shock and laughter from the group with several other students also confessing to skipping almost an entire semester's worth of classes. Professor D retorted by saying, perhaps "you don't know whether or not it is interesting until you do the readings." Student $\mathrm{H}$ suggested that interest comes from a student's search for the "relevancy" of the reading within the text itself and also from the pedagogy of the class. A discussion-based class, he proffered, only becomes "interesting" if you have done the reading and can interact with your classmates and teacher; a student who has "to go there and just listen to the lecture" for a compulsory course may find no "relevancy" in either the content or the method through which it is delivered.

Student F's brazen admissions of refusal challenged stereotypes of both the "Hong Kong student" (commonly understood to be passive to the point of silence, pragmatic, and skilled in rote memorization) and the "ideal student." Her resistant language, defiance, and confidence illustrate how students often do not communicate "in a certain way about their learning with the teacher using appropriate language forms" (Arnot \& Reay, 2007 p. 321). Student Consultants specialize in such "code talk" (Arnot \& Reay, 2007, p. 319) through which faculty and administrators might more readily hear advice and preferences, but Student $F$ demanded that we also listen to the undisciplined voices, unschooled and resistant to pedagogic process. How do we hear the student who is "not interested"? As with "ineffective," the term "interesting" elicited a range of perspectives from students and faculty as they unpacked their different assumptions-differences that initially presented obstacles to partnership.

\section{Receptivity that Leads to Partnership}

After trying to understand gestures of refusal from students, Professor A eventually asked for "solutions" to his struggles with varying levels of "interest" and investment in his course, and he wanted to know how he can help students complete assigned reading as a prerequisite for critical thinking. At this point in the discussion, I noticed a general loosening of tension in the group as students seized the opportunity to give advice and share their insights, a practice that, beyond the Student Consultant Program, many do not have consistent access. 
The students' responses addressed the accountability of both parties in the crafting of effective and "interesting" assignments. One student, for example, suggested that "you can ask them to write them to write their own questions" to foster choice, independence, and ownership of learning outside of class. At least three students offered anecdotes about compulsory courses they have attended where the teacher's "passion" and "caring" inspired them to participate and become engaged. Despite "hating science," Student F attends all her biology classes because her professor is "so passionate in teaching, and you feel bad [about] not doing the homework that he asked you to do, so I ended up doing the homework which is not graded." A Student Consultant similarly described her experience in a history tutorial where the professor succeeded in getting her to read by "caring" and having "passion towards the class that he teaches, especially when it is a compulsory subject."

As I listened to these student perspectives, I felt daunted: How does a teacher recreate passion in every class? How does caring translate to assessment? Do students only participate out of pity for their professors or because passion is infectious? Thinking further, however, I realized that these comments highlight the powerful intersection of pedagogy and passion: professors manage to get and keep students' attention by modeling commitment both to the class and the discipline, stimulating engagement, and fostering partnership and students' ownership of the course. This combination also applies to how homework is assigned - the ideal is not the absence of homework but an assignment in the individual style of the professor to suit what is unique to the course. Student $F$ described how homework can be a way of "learning [it] in the eyes of the person . . . because every individual, every professor, has their own special features." Students, it seems, seek the same kind of originality and independent thought in assigning homework that teachers value in the homework answers students give.

Once we turned off the recorders and the group disbanded, Professor A became locked in conversation with four of the student participants whom he had just met. Sensing his culture shock, the students were eager to continue the conversation with him, offering encouragement and advice about maintaining his individuality as a teacher. Seeing this engagement, we realized that we had achieved what we had set out to do: in one hour, we had managed to break down boundaries between faculty and students and create spontaneous sharing. The open sharing in which students engaged, and the ultimately open mind that Professor $A$ demonstrated in staying behind to talk with the students, constituted small, but significant, steps on the way to an ethos of partnership.

\section{CONCLUSION}

Scholars and advocates of student voice work caution against what Michael Fielding has defined as "methodologies or contextual circumstances [that] reinforce subjugation" (2004, p. 296) and resting on (than critically addressing) assumptions that might lead to further marginalization or manipulation. At every moment of this focus group and while drafting this essay, I have tried to remain attuned to "who is speaking, who is spoken of and who listens as a result" (Alcoff qtd. in Fielding, 2004, p. 301) as well as the "historical location of the structures and relations of power" (p. 301).

In this case, students and faculty operate under the neoliberal economics of Hong Kong's postcolonial educational complex and the political dynamics of a university system 
reacting to a post-Umbrella Movement student population. During the focus group, I witnessed students refusing to be interrupted and helping each other clarify their thoughts and preferences in dialogue with professors who took up the responsibility of being active listeners. While I have not yet followed up on whether faculty have acted on what they have heard, we have nonetheless gone some way in undoing the image that endures from the unproductive meeting between student leaders and government officials during the pro-democratic Umbrella Movement in 2014. During the Umbrella Movement, a last-ditch dialogue was arranged between pro-democracy student leaders and government officials. The images released from the event illustrate the many obstacles facing partnership in the territory. A chasm separates the two parties, reinforcing the divide between who speaks and who is heard. ${ }^{3}$

This focus group demonstrated how powerful active listening, often on the part of adults/teachers, can be in facilitating partnership because it creates a climate of openness. At the same time, overcoming deeply ingrained assumptions, often about the student/other, can be a challenge to hearing and receptivity. While attentive to the complicated power dynamics of what Julie McLeod (2011) has called "voice-based equity interventions" (187), I felt like we co-created, if only temporarily, a more democratic, postcolonial space centered on openness, difference, and collaboration. The focus group on homework, in which we encountered obstacles but also opened our minds, constituted small steps toward an ethos of partnership in our Hong Kong university.

\section{ACKNOWLEDGEMENTS}

I would like to thank the following students for organizing and facilitating the focus group: Vivian Lam Weng Yan, Kourtney Woo Lok Shan and Esther Shek Long Yin. Further thanks to Nicol Cheung, Karen Lee Ka Lam, Tina Lam Kun Kam and Coco Chan Hok Wan. Special thanks to Vivian Lam for transcribing the focus group recordings. These students were unable to coauthor this article, unfortunately, due to the amount of homework they had!

\section{NOTES}

1. The Ursinus program, in turn, was based on Bryn Mawr College's Students as Learners and Teachers (SaLT) program.

2. In 2012, the Hong Kong government radically moved from a 3-year university curriculum to a 4-year system. The so-called "3-3-4" reforms were designed to increase global competitiveness in graduates and bring Hong Kong in line with international standards. Similar to the North American educational system, Hong Kong students gain a year of core curriculum courses prior to choosing their majors.

3. http://www.scmp.com/news/hong-kong/article/1621694/talks-fail-narrow-gap-betweenstudent-leaders-and-government

NOTE ON CONTRIBUTOR

Elizabeth Ho is Assistant Professor in the Department of English at Hong Kong University. 


\section{REFERENCES}

Arnot, M., \& Reay, D. (2007). A sociology of pedagogic voice: Power, inequality and pupil consultation. Discourse: Studies in the Cultural Politics of Education, 28(3), 311-325.

Fielding, M. (2004). Transformative approaches to student voice: Theoretical underpinnings, recalcitrant realities. British Educational Research Journal, 30(2),295-311.

McLeod, J. (2011). Student voice and the politics of listening in higher education. Critical Studies in Education, 52(2), 179-189.

Pounder, J. S., Ho, E. H., \& Groves, J. M. (2015). Faculty-student engagement in teaching observation and assessment: A Hong Kong initiative. Assessment \& Evaluation in Higher Education, 41(8), 1193-1205. 